\title{
SHORT TERM EVALUATION OF \\ INTEROCCLUSAL DISTANCE DURING \\ SPEECH AFTER NEW REMOVABLE \\ PROSTHESIS INSERTION
}

\author{
AVALIAÇÃO A CURTO PRAZO DA DISTÂNCIA INTEROCLUSAL \\ APÓS A INSTALAÇÃO DE NOVAS PRÓTESES REMOVÍVEIS
}

\author{
Renata Cunha Matheus Rodrigues GARCIA \\ PhD Associate Professor, Department of Prosthodontics and Periodontology, School of Dentistry of Piracicaba, University of Campinas. \\ Viviane Maia Barreto OLIVEIRA \\ DDS, MS Graduate Student, Department of Prosthodontics and Periodontology, School of Dentistry of Piracicaba, University of Campinas. \\ Altair Antoninha DEL BEL CURY \\ PhD Associate Professor, Department of Prosthodontics and Periodontology, School of Dentistry of Piracicaba, University of Campinas.
}

\begin{abstract}
$T$ he aim of this study was to evaluate the interocclusal distance during the pronunciation of $/ \mathrm{m} / \mathrm{and} / \mathrm{s} / \mathrm{sounds}$ from Portuguese Language, in partially edentulous patients before and after new partial and total prosthesis installation. The subjects were divided into two groups: Experimental group, consisting of 9 patients entirely edentate in the upper maxillary arch and classified as Kennedy Class I in the lower arch; and Control group, consisting of 9 totally dentate patients. The subjects from the first group had their worn out dentures changed and the occlusal vertical dimension (OVD) corrected. A magnetic method of jaw tracking was used to measure the interocclusal distance $(\mathrm{mm})$ during pronunciation of those phonemes. Comparison between groups, by $t$ test, showed significant difference $(p<0.05)$ for $/ \mathrm{m} /$ sound in all periods of time: before prosthesis installation $-\mathrm{T} 0(3.38 \pm 1.23)$, immediately - T1 (2.15 \pm 1.06$)$, six hours - T2 (3.41 \pm 1.33$)$, twenty-four hours - T3 (2.92 \pm 0.92$)$, two days $-\mathrm{T} 4$

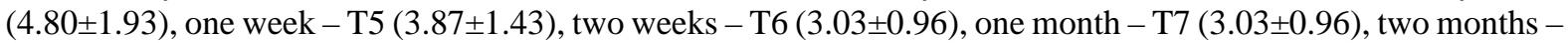
$\mathrm{T} 8(4.47 \pm 1.45)$ and three months $-\mathrm{T} 9(4.33 \pm 2.56)$, except for six months $-\mathrm{T} 10$ after prosthesis installation. For $/ \mathrm{s} /$ sound phoneme the results were different $(p<0.05)$ between the groups in T1 $(2.89 \pm 1.33)$, T2 $(3.37 \pm 1.22)$, T3 (3.19 \pm 1.06$), \mathrm{T} 4(3.86 \pm 1.21), \mathrm{T} 5(3.83 \pm 1.32), \mathrm{T} 6(3.27 \pm 1.10), \mathrm{T} 7(3.37 \pm 0.99)$ and T10 $(3.84 \pm 1.38)$ after oral rehabilitation. The paired- $t$ test, for means comparison between before and after prosthesis insertion, indicated significant differences $(p<0.05)$ for $/ \mathrm{m} /$ sound only in T1, and for $/ \mathrm{s} /$ sound in T1, T2, T3, T6, T7 and T10. It was concluded that new prosthesis insertion, correcting the OVD, changes the interocclusal distance, and for $/ \mathrm{m} /$ sound this distance could be recovered after six months of prosthesis wearing.
\end{abstract}

UNITERMS: Occlusal vertical dimension; Speech; Interocclusal distance.

\section{INTRODUCTION}

Increasing occlusal vertical dimension (OVD) can affect speech articulation of some sounds ${ }^{8}$. Silverman ${ }^{13}$ (1953) was the first to suggest that a relationship may exist between the closest speaking space (CCS) and the occlusal vertical dimension. He noted that the sibilant sounds from English language produced the closest speaking space, but stated that this measure must not be confused with the interocclusal rest space (IORS), because these measures are different for the same patient.

However, the hypothesis that the CCS could be smaller than IORS have been contested, and recent studies have verified that there are no statistical differences between these two measures during the pronunciation of some sounds ${ }^{11}$, because they are not different physiologic phenomena ${ }^{12}$. In addition, the 
minimal electromyographical activity (EMG) of some masticatory muscles does not usually correspond to the clinical rest position ${ }^{10}$.

It is recognized that the CSS can vary among idioms and according to $\mathrm{Lu}$, et al. ${ }^{9}$ (1993) there are differences in the CSS between English and Cantonese languages. As the CSS is produced during sibilants sounds pronunciation ${ }^{9,12,14}$, some authors considered it as being equivalent to the interocclusal distance during speech of $/ \mathrm{m} /$ and $/ \mathrm{s} /$ phonemes.

Current clinical and research emphasis is primarily on English language. Because every person who wears new dentures must adapt to OVD and speech changes, additional descriptive clinical data are needed to assess the time and relative significance of this occurrence.

The aim of this study was to evaluate the shortterm effects of increasing oclusal vertical dimension on interocclusal distance (IOD), during the speech of $/ \mathrm{m} /$ and $/ \mathrm{s} /$ sounds from Portuguese language, by the new partial and total removable prosthesis insertion, using a magnetic method of jaw tracking.

\section{MATERIALS AND METHODS}

\section{Subjects}

Twenty-one volunteers participated in this study and were divided into two groups. Only healthy subjects without systemic disease were included and none suffered from any speech defect or had a history or symptoms of temporomandibular dysfunction. The first group, or control group, consisted of 2 male and 7 female undergraduate dental students and employees at the School of Dentistry of Piracicaba, University of Campinas (mean age 38 years). This entire group had intact dentitions, except where extractions for orthodontic realignment had been performed or third molars were missing.

The second, or experimental group, consisted of 1 male and 11 female, who were selected from those treated at the Dental Clinic from the School of Dentistry of Piracicaba (mean age 53 years). The criteria for selection to this group were that each subject should: (1) have previously worn a conventional upper complete denture; (2) have OVD altered by the use of old and worn out dentures; and (3) be partly dentate in the lower dental arch, classified as Kennedy Class I. All selected subjects signed a consent form.

\section{Removable Prosthesis Preparation}

After selection, the patients from the experimental group received new upper complete dentures and lower partial dentures prepared with a heat polymerized acrylic resin (Clássico Artigos Odontológicos Ltda., São Paulo, Brazil), according to the conventional technique. All lower partial denture frameworks were prepared in a cobalt-chromium (Co-Cr) (Degussa Hüls AG, Hanau, Germany) and the major connector planned for all of them was the lingual bar. The OVD was determined by two methods: (1) Willis and (2) Turner \& Fox. These two methods were applied for each patient, and the OVD used was that when an agreement value was obtained from both methods.

After prosthesis insertion, three patients of experimental group abandoned the research, thus the study was conducted with a total of 18 subjects, comprising nine patients in each group.

\section{Interocclusal Distance Evaluation}

The magnetic method of jaw tracking was used to record mandibular movement to determine the interocclusal distance for both control and experimental groups, before and after prostheses insertion. The records were obtained by a Kinesiograph (K6-I Evaluation System, MyotronicsNoromed Inc, Seatle, WA, U.S.A.) using a scan number 3 with $5 \mathrm{~mm}$ of magnification. This method is an integrated computerized system designed for the specific purpose of monitoring mandibular movement in three dimensions. The specific mechanisms utilized by the K6-I System for tracking movement are derived from the field of alectromegnetic proximity measurement.

The subjects worn an array of sensors suspended on a lightweight headgear, which is sensitive to alterations of a magnetic field (Figure 1). A magnet was affixed in the patient's labial vestibule, just below the mandibular incisors (Figure 2). The sensor array then tracks the movements of the mandible from the incisor point.

Therefore, the subjects were placed with the Frankfort plane horizontal, with a firm headrest, and instructions to avoid head movements. They were asked to close to the maximum intercuspal position (MIP), this position was explained and demonstrated prior to the experiment. They were then asked to speech for 10 times the phoneme $/ \mathrm{m} /$ from the Portuguese language at normal conversation rate and volume, until the equipment provided the interocclusal distance values, and then asked to return to the MIP 
position. The same procedure was followed in order to record the interocclusal distance for /s/ speech sound.

The interocclusal distance was determined for the experimental group, in the following periods of time: immediately before prosthesis insertion (T0), but without the old prosthesis in the mouth; immediately after the new prosthesis insertion (T1); six hours after (T2); 24 hours after (T3); two days after (T4); one week after (T5); two weeks after (T6); one month after (T7); two months after (T8); three months after (T9); and six months after (T10) prosthesis installation. Since the patients of control group did not receive any prosthetic treatment, they were evaluated in a single period of time.

\section{Statistical Analysis}

The means of the measurement of the interocclusal distance recorded for $/ \mathrm{m} /$ and $/ \mathrm{s} /$ sounds from the control group was compared with those obtained from experimental group by $t$ test at $95 \%$ of confidence

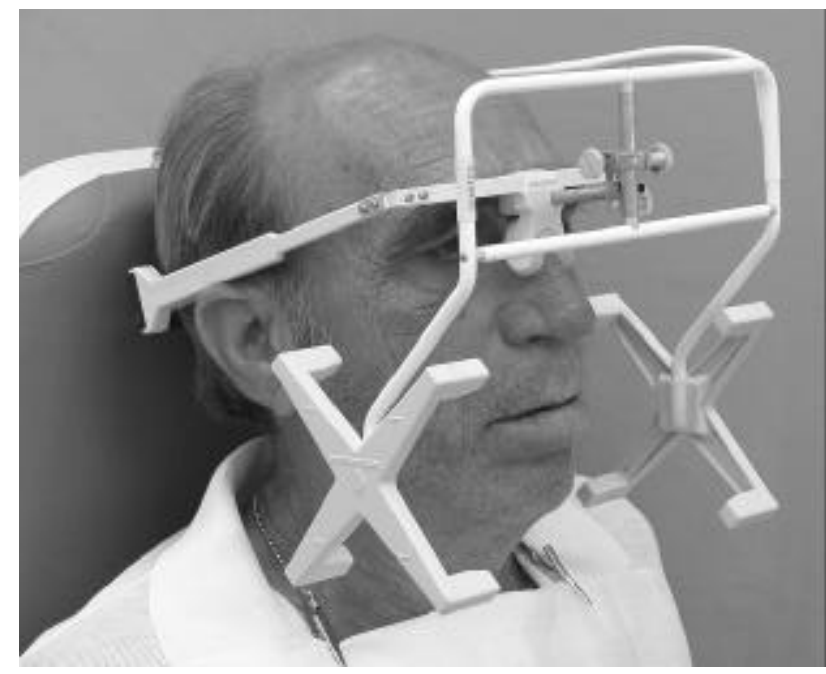

FIGURE 1- Subject using an array of magnetic sensors.

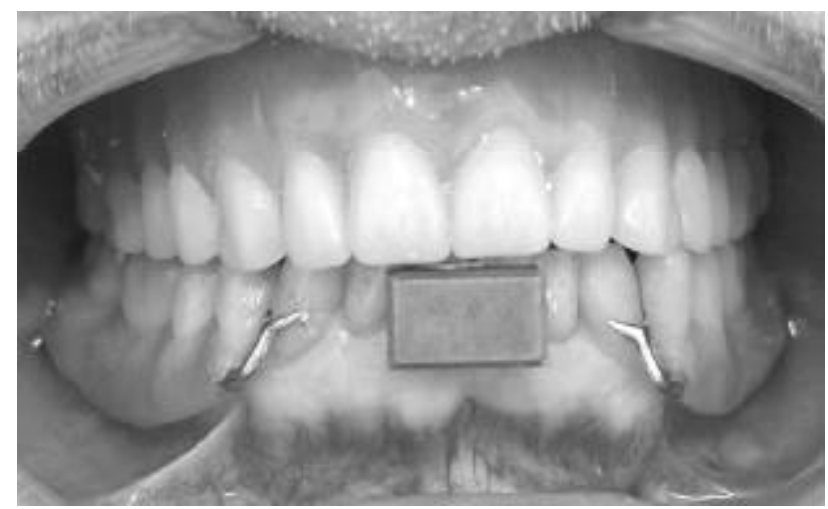

FIGURE 2- Magnet affixed in the patient's labial vestibule. level. The mean value of interocclusal distance before the new prosthesis insertion (T0) was then compared with those recorded after several times of prosthesis insertion (T1, T2, T3, T4, T5, T6, T7, T8, T9 and T10) using a paired $t$ test, at the same level of confidence.

\section{RESULTS}

Table 1 shows the means of interocclusal distance (mm) determined for each period of time, during $/ \mathrm{m} /$ sound speech for control and experimental groups. There was a variation between periods of time ranging from 2.15 to 5.13 . There was statistical difference, $p<0.05$, for the interocclusal distance values between the control and experimental groups, in all periods of time studied, except for T10, six months after prosthesis installation. A paired $t$ test showed a statistically significant difference, $p<0.05$, for the mean values of the interocclusal distance between $\mathrm{T} 0$ and $\mathrm{T} 1$ only.

Table 2 shows the comparisons of interocclusal distance values obtained during pronunciation of $/ \mathrm{s} /$ sound. The values ranged from 5.04 to 2.89 with the time. There were statistical differences, $p<0.05$, between control and experimental groups in the following periods of time: T1 (immediately after prosthesis insertion), T2 (six hours after), T3 (24 hours after), T4 (two days after), T5 (one week after), T6 (two weeks after), T7 (one month after) and T10 (six months after). A paired $\mathrm{t}$ test showed differences, $p<0.05$, between the values obtained in T0 (before prosthesis insertion) and T1, T2, T3, T6, T7 and T10.

\section{DISCUSSION}

A newly acquired prosthesis or orthodontic appliance requires a period of physiologic adjustment by the patient. This adjustment, or adaptation is accomplished through functional alterations, including efficient chewing, swallowing and speech articulation ${ }^{6}$.

Interocclusal distance during $/ \mathrm{m} /$ and $/ \mathrm{s} /$ sounds from Portuguese language pronunciation, obtained before and several periods after removable prosthesis insertion, were compared with those obtained from complete dentate patients. This comparison was an attempt to verify in which period of the time similar measures between the groups could occur, indicating a possible phonetic adaptation to the new prosthesis.

The results from $/ \mathrm{m} /$ sound (Table 1 ) indicated significant difference $(p<0.05)$ for IOD values between 
experimental and control groups only after six months of prosthesis installation (T10). It is likely that the wearer of a new mandibular partial removable prostheses, and a maxillary complete denture needs nearly 6 months to pronounce $/ \mathrm{m} /$ phoneme similarly to a complete dentate patient.

According to Mehringer ${ }^{11}$ (1963) the nasal sonant sounds need an incisal separation of 2 to $4 \mathrm{~mm}$, equivalent to the IOD when the mandible is physiologically at rest, and are emitted through the

TABLE 1- Means and Standard Deviations of Interocclusal Distance $(\mathrm{mm})$ During $/ \mathrm{m} /$ Sound Pronunciation, Before and After New Prosthesis Insertion.

\begin{tabular}{|c|c|c|}
\hline \multirow[b]{3}{*}{ Time } & \multicolumn{2}{|c|}{ /M/ PHONEME } \\
\hline & Experimental Group & Control Group \\
\hline & Mean (SD) & Mean (SD) \\
\hline & & $6.94(2.17)$ \\
\hline T0 (Before rehabilitation) & $3.38(1.23)$ * & \\
\hline T1 (Immediately after) & $2.15(1.06)^{*} \dagger$ & \\
\hline T2 (Six hours after) & $3.41(1.33)$ * & \\
\hline T3 (24 hours after) & $2.92(0.92) *$ & \\
\hline T4 (Two days after) & $4.80(1.93)^{*}$ & \\
\hline T5 (One week after) & $3.87(1.43)$ * & \\
\hline T6 (Two weeks after) & $3.03(0.96)$ * & \\
\hline T7 (One month) & $3.03(0.96)$ * & \\
\hline T8 (Two months after) & $4.47(1.45)^{*}$ & \\
\hline T9 (Three months after) & $4.33(2.56)^{*}$ & \\
\hline T10 (Six months after) & $5.13(2.25)$ & \\
\hline
\end{tabular}

Means followed by * are different $(p<0.05)$ from the control group by $t$ test

Means followed by $\dagger$ are different $(p<0.05)$ from T0 (before rehabilitation), by $t$-paired test.

TABLE 2- Means and Standard Deviations of Interocclusal Distance (mm) During /s/ Sound Pronunciation, Before and After New Prosthesis Insertion.

\begin{tabular}{|c|c|c|}
\hline \multirow[b]{3}{*}{ Time } & \multicolumn{2}{|c|}{ /M/ PHONEME } \\
\hline & Experimental Group & Control Group \\
\hline & Mean (SD) & Mean (SD) \\
\hline & & $5.61(2.04)$ \\
\hline T0 (Before rehabilitation) & $5.04(1.49)$ & \\
\hline T1 (Immediately after) & $2.89(1.33)^{*} \dagger$ & \\
\hline T2 (Six hours after) & $3.37(1.22) * \dagger$ & \\
\hline T3 (24 hours after) & $3.19(1.06)^{*} \dagger$ & \\
\hline T4 (Two days after) & $3.86(1.21)^{*}$ & \\
\hline T5 (One week after) & $3.83(1.32) *$ & \\
\hline T6 (Two weeks after) & $3.27(1.10)^{*} \dagger$ & \\
\hline T7 (One month) & $3.37(0.99)^{*} \dagger$ & \\
\hline T8 (Two months after) & $3.93(1.42)$ & \\
\hline T9 (Three months after) & $4.01(1.62)$ & \\
\hline T10 (Six months after) & $3.84(1.38)^{*} \dagger$ & \\
\hline
\end{tabular}

Means followed by * are different $(p<0.05)$ from the control group by $t$ test.

Means followed by $\dagger$ are different $(p<0.05)$ from T0 (before rehabilitation), by $t$-paired test. 
nose. In the format of $/ \mathrm{m} /$ sound, the closed lip position obstructs the oral port. The tongue rests on the floor of the mouth creating a space between it and the palate. This space acts as a resonating chamber for the low frequency vibration in the speech. Therefore, with the new prosthesis installation, besides the OVD, this resonating chamber space was altered, originating speech problems during the first periods after prosthesis insertion.

Hamletm, Stone ${ }^{7}$ (1982) stated that dentate patients need a period of two or more weeks in order to adapt to dimensional and shape changes of the palate and alveolar region, and return to speech properly. In addition, according to Hammond and $\operatorname{Beder}^{8}(1984)$ the loss of teeth alters not only the dimensions of the oral cavity, but also results in loss of the tooth proprioception, which exerts a physiologic influence on speech articulation. Considering that patients evaluated in this study were complete-denture wearers, they consequently showed alterations in both dimension of the mouth and proprioception mechanism. Therefore, they would need a longer period of time, nearly 6 months in order to exhibit the same interocclusal distance during $/ \mathrm{m} /$ sound pronunciation, as the dentate patients.

Comparison of IOD values for $/ \mathrm{m} /$ sound, between before and after prosthesis insertion (Table 1), revealed statistical difference $(p<0.05)$ only for T1 (immediately after prosthesis installation). This means that immediately after prosthesis insertion, the IOD was altered and in the following periods of time it returned to the same values as before rehabilitation. As the articulation of $/ \mathrm{m} /$ sound depends mainly on the space created between the tongue and palate, the patient should be able to pronounce this phoneme reproducing the IOD value obtained before oral rehabilitation, in a short period of time. This fact does not mean that this measure is equal to that obtained from the control group patients.

To speech /s/ sound, the mandible should be depressed and slightly protracted until an incisal separation of 1 to $1.5 \mathrm{~mm}$ is attained ${ }^{11}$. The tongue rests against the lingual of the lower anterior teeth and at the same time contacts the lateral portions of the palate. Thus, the emission of this sound, a minimal incisal separation must exist, and consequently the position of anterior upper and lower teeth is an important factor.

However, the results from the comparison between experimental and control groups (Table 2) showed that the IOD values obtained during the pronunciation of this sibilant sound were not statistically different ( $p>0.05$ ) before prosthetic treatment (T0). This result could be related to the space needed to speech this sound. In the experimental group, before prosthesis installation, this space occurred between superior alveolar ridge and incisal surface of anterior lower teeth. Probably, this space measure is similar to that obtained from dentate patients, and it is the most relevant change caused by a prosthesis insertion than any others.

It can also be noted in Table 2 that after prosthesis insertion, from $\mathrm{T} 1$ to $\mathrm{T} 7$, the results were different $(p<0.05)$ between the groups. Again, this could be explained by the oral cavity dimensions and OVD alterations right after prosthesis insertion. Along the time, from $\mathrm{T} 1$ to $\mathrm{T} 7$, the progressive neuromuscular adaptation ${ }^{8}$ could allow the patient to adapt to a new OVD, recovering the IOD needed to speech /s/ sound. The IOD recovering could be complete after two or three months of prosthesis insertion, since the values were not different $(p>0.05)$ between groups.

However, as the /s/ sound is more affected than the $/ \mathrm{m} /$ sound after prosthesis treatment ${ }^{3,14,15}$, the total adaptation could not be complete, because after six months (T10), the results were again statistically different $(p<0.05)$ between the groups. Therefore, the speech adaptation for sibilants sounds is probably more complex, and the patient needs a longer period of time to recover the IOD, required to emit this sound.

The analysis of IOD values obtained for the experimental group, showed significant differences $(p<0.05)$ between T0 (before treatment) and T1, T2, T3, T6, T7 and T10 periods of time after prosthesis insertion. This could be expected, since the speech adaptation to /s/ sound is more complex and needs a longer period of time to be evaluated.

The IOD values for both sounds obtained for the control group in this study, were different from those found by Lu, et al. ${ }^{9}(1993)$, Burnett and Clifford ${ }^{1}$ (1993) and Burnett ${ }^{2}$ (2000), probably due the different idioms studied. In addition, according to George ${ }^{5}$ (1983), IOD for /s/ sound can vary depending on its position in a word or phrase. This present study has evaluated the emission of a phoneme alone, and this fact could contribute to explain the differences found.

Besides all factors previously reported, the patient emotional behavior in relation to a prosthetic treatment can also influence the speech patterns ${ }^{4,15}$. Patients who psychologically accepted their dentures, shortly after they started wearing them, also had fewer speech difficulties than those who did not accept the dentures. Thus, the speech alterations after removable or fixed oral rehabilitations are complex and need further studies involving longer periods of evaluation. 


\section{CONCLUSIONS}

Within the limitations of this investigation, the following conclusions can be drawn:

1. The oclusal vertical dimension correction by a new complete upper dentures and partial removable lower prosthesis insertion, can alter the interocclusal distance needed to speech $/ \mathrm{m} /$ and $/ \mathrm{s} /$ sounds from Portuguese language.

2. The interocclusal distance needed to speech / $\mathrm{m} /$ sound from Portuguese language was recovered after six months of prosthesis wearing.

3. The freeway space necessary for $/ \mathrm{s} /$ sound pronunciation needs a longer period of time to be recovered.

\section{RESUMO}

O objetivo deste estudo foi avaliar a distância interoclusal durante a pronúncia dos fonemas $/ \mathrm{m} / \mathrm{e} /$ s/ da Língua Portuguesa em pacientes parcialmente desdentados antes e após a instalação de novas próteses parciais inferiores e totais superiores. Os voluntários foram divididos em dois grupos: Grupo Experimental: composto por 9 pacientes totalmente desdentados na arcada dentária superior, e classificados como classe I de Kennedy na arcada dentária inferior; e Grupo Controle, composto por 9 pacientes totalmente dentados. Os voluntários do primeiro grupo tiveram suas próteses antigas substituídas e a dimensão vertical de oclusão (DVO) corrigida. O método eletromagnético do traçado dos movimentos mandibulares foi utilizado para mensurar a distância interoclusal $(\mathrm{mm})$ durante a pronúncia dos referidos fonemas. A comparação dos resultados entre os grupos (teste " $\mathrm{t}$ ") demonstrou diferença significante $(\mathrm{p}<0,05)$ para o fonema $/ \mathrm{m} /$ em todos os períodos de tempo avaliados: antes da instalação das próteses - T0 $(3,38 \pm 1,23)$, imediatamente $-\mathrm{T} 1(2,15 \pm 1,06)$, seis horas - T2 $(3,41 \pm 1,33), 24$ horas - T3 $(2,92 \pm 0,92)$, dois dias - T4 $(4,80 \pm 1,93)$, uma semana - T5 $(3,87 \pm 1,43)$, duas semanas - T6 $(3,03 \pm 0,96)$, um mês - T7 $(3,03 \pm 0,96)$, dois meses - T8 $(4,47 \pm 1,45)$ e três meses - T9 $(4,33 \pm 2,56)$, exceto para o tempo de seis meses - T10, após a instalação das próteses. Para o fonema /s/, os resultados indicaram diferenças estatísticas $(\mathrm{p}<0,05)$ entre os grupos em T1 $(2,89 \pm 1,33), \mathrm{T} 2(3,37 \pm 1,22), \mathrm{T} 3(3,19 \pm 1,06), \mathrm{T} 4$ $(3,86 \pm 1,21), \mathrm{T} 5(3,83 \pm 1,32), \mathrm{T} 6(3,27 \pm 1,10), \mathrm{T} 7$ $(3,37 \pm 0,99)$ e T10 $(3,84 \pm 1,39)$ após a reabilitação oral. O teste "t-pareado", utilizado para a comparação das médias entre antes e após a inserção das próteses, indicou diferenças significantes $(\mathrm{p}<0,05)$ para o fonema $/ \mathrm{m} /$ somente em $\mathrm{T} 1$, e para o fonema $/ \mathrm{s} / \mathrm{em}$ T1, T2, T3, T6, T7 e T10. Pode-se concluir que a instalação de novas próteses, corrigindo a DVO, altera a distância interoclusal, e que para o fonema $/ \mathrm{m} /$ esta distância pode ser recuperada após 6 meses de uso das próteses.

UNITERMOS: Dimensão vertical de oclusão; Fala; Distância interoclusal.

\section{ACKNOWLEDGMENT}

The authors wish to express sincere appreciation to Dr. Jaime A. Cury who provide an office to develop this research.

\section{REFERENCES}

1- Burnett CA, Clifford TJ. Closest speaking space during the production of sibilant sounds and its value in establishing the vertical dimension of occlusion. J Dent Res 1993; 72:964-7.

2- Burnett CA. Clinical rest and closest speech positions in the determination of occlusal vertical dimension. J Oral Rehabil 2000; 27:714-9.

3- Chaney SA, Moller KT, Goodkind RJ. Effects of immediate dentures on certain structural and perceptual parameters of speech. J Prosthet Dent 1978; 40:8-12.

4- Chierici G, Lawson L. Clinical speech considerations in prosthodontics: perspectives of the prosthodontist and speech pathologist. J Prosthet Dent 1973; 29:29-39.

5- George JP. Using the kinesiograph to measure mandibular movements during speech: a pilot study. J Prosthet Dent 1983; 49:263-70.

6- Hamlet SL, Stone M, Mc Carty T. Conditioning prostheses viewed from the standpoint of speech adaptation. J Prosthet Dent 1978; 40:60-6.

7- Hamlet SL, Stone M. Speech adaptation to dental prostheses: the former lisper. J Prosthet Dent 1982;47:564-9.

8- Hammond RJ, Beder OE. Increased vertical dimension and speech articulation errors. J Prosthet Dent 1984; 52:401-6.

9- Lu GH, Chow TW, So LKH, Clark RKF. A computer-aided study of speaking spaces. J Dent 1993; 21:289-96.

10- Manns A, Miralles R, Guerrero F. The changes in electrical activity of the postural muscles of the mandible upon varying the vertical dimension. J Prosthet Dent 1981; 45:438-45.

11- Mehringer EJ. The use of speech patterns as an aid in prosthodontic reconstruction. J Prosthet Dent 1963; 13:825-37. 
12- Rivera-Morales WC, Mohl ND. Variability of closest speaking space compared with interocclusal distance in dentulous subjects. J Prosthet Dent 1991; 65:228-32.

13- Silverman MM. The speaking method in measuring vertical dimension. J Prosthet Dent 1953; 3:193-9.

14- Silverman MM. The whistle and swish sound in denture patients. J Prosthet Dent 1967;17:144-8.

15- Troffer C, Beder OE. Immediate dentures and speech defects Dental Progress 1961; 1:264-9.

Recebido para publicação em: 08/05/2003

Aceito após reformulações em: 12/08/2003

\section{Correspondence to:}

Renata Cunha Matheus Rodrigues Garcia

Address: Rua Fernando Febeliano da Costa, 1799, Apto. 31

Piracicaba, São Paulo - Brazil - 13416-250

Phone/Fax: 5519 3434-9107

Office Phone: 5519 3412-5294

e-mail: regarcia@fop.unicamp.br 